\title{
Team Change at the Journal of Chemical Sciences
}

With this issue of the Journal (Vol. 125, No. 4, July 2013) we welcome a new Chief Editor, Prof. N Periasamy who has taken over from 1 July. The Editorial Board also welcomes some new members into its fold.

For the past twelve years, Prof. S S Krishnamurthy has steered the journal very ably. The Journal has achieved significant progress in its techniques of production, in its visibility within the country as well as abroad, and in its methods of dissemination. Since the Academy's collaboration with Springer, the use of an online submission and peer review management system has enabled rapid and trackable processing of manuscripts. All these have helped to ensure a global reach and impact through worldwide visibility. About 850 papers were submitted to the Journal in 2012 and the number promises to increase each year. The total download figures for 2012 have crossed 47,000 and the impact factor is now 1.298 .

On behalf of the President and the Council, I take this opportunity to thank Prof. S S Krishnamurthy for his sterling contributions to the Journal. We thank the incoming Chief Editor, Prof. N Periasamy and look forward to his leadership and guidance. Our thanks also to the new members of the Editorial Board, as well as the new Associate Editors.

July 2013

R Ramaswamy

Editor of Publications 